\title{
Fostering Learning Capacities for Meaningful, Healthy and Efficient Studying in Undergraduate Medical Education - Evaluation of a Longitudinal Learning Workshop
}

Miriam Thye ( $\square$ miriam.thye@uni-wh.de )

Witten/Herdecke University

Diethard Tauschel

Witten/Herdecke University

\section{Research Article}

Keywords: learning, learning life, undergraduate medical education, medical students, didactics, qualitative research, self-regulation, self-determination, self-care

Posted Date: March 15th, 2021

DOI: https://doi.org/10.21203/rs.3.rs-257745/v1

License: (c) (i) This work is licensed under a Creative Commons Attribution 4.0 International License.

Read Full License 


\title{
Fostering learning capacities for meaningful, healthy and efficient studying in undergraduate medical education - Evaluation of a longitudinal learning workshop
}

\author{
Miriam Thye $\mathrm{e}^{1,2^{*}}$ and Diethard Tauschel ${ }^{1}$
}

\section{"Correspondence: \\ miriam.thye@uni-wh.de \\ Witten/Herdecke University, \\ Faculty of Health, Department of \\ Medicine, Integrated Curriculum \\ for Anthroposophic Medicine \\ (ICURAM) \\ ${ }^{2}$ Witten/Herdecke University, \\ Faculty of Health, Department of \\ Psychology and Psychotherapy \\ Full list of author information is} available at the end of the article

\begin{abstract}
Background:

Medical studies place high demands on the development of learning capacities. Learning environment, self-regulation, self-determination and self-care play a major role in this context. Impaired health of students in particular has a negative impact on learning and subsequent professional life. Learning life can be defined as the sum of all the factors influencing the students' entire life; this includes physical, physiological, psychological and mental dimensions of learning. This study describes and evaluates a longitudinal learning workshop for undergraduate medical students which aims to foster academic learning life with an anthropologically grounded holistic approach.

\section{Methods:}

Fifty evaluations by medical students underwent a qualitative analysis of open-ended questions concerning their experienced changes in their learning life. In addition, general satisfaction with the learning workshop was measured quantitatively.

Results:

Qualitative results revealed an impact on five core dimensions of medical students' learning: knowledge, awareness, action, experience and regulation. Quantitative results demonstrated good overall satisfaction.

\section{Conclusions:}

Taking students' physiology, body, psychology and mentality into account within a seven weeks longitudinal learning workshop, impact on the fields of knowledge, awareness, action, experience and regulation can be achieved. To support the multidimensional learning life of medical students, a holistic approach could be considered as an enhancement to foster healthy, meaningful and efficient ways of learning. Thus, this learning workshop seems to be a useful and transferable tool to support medical students' learning.
\end{abstract}

Keywords: learning, learning life, undergraduate medical education, medical students, didactics, qualitative research, self-regulation, self-determination, self-care.

\section{Background}

Medical studies and the formation of a physician identity place high demands on the development of comprehensive and efficient learning skills. Learning is not only about acquisition of knowledge and preparation for the next examination; learning is a lifelong reflective and adaptive process of change and formation [1]. A fundamental element of learning is the learning environment [2]. This involves specific surrounding factors such as a quiet work atmosphere, social support, as well as self-regulation in terms of daily learning periods. Such a learning approach - which facilitates the perception of knowledge acquisition not as superficial, but as a thorough and long-term process leading up to transfer - also includes factors of health and life-style, like sufficient sleep, exercise and diet [3]. Therefore, health plays an essential role in connection with a student's learning environment. 
Medical students and doctors report deficits with regard to health, meaningfulness, and joy [4], as well as poor quality of life [5]. Medical students' perceived stress and emotional distress levels are high compared to the general population [6]. Described possible consequences are loss of empathy, cynicism, burnout, depression, somatic illnesses, or substance abuse [7-9]. Every second medical student experiences a burnout during the course of medical training [10]. In a systematic review, Mata et al. describe a prevalence of depression between $20.9 \%$ and $43.2 \%$ in young physicians which is high compared to the peer group. The authors report instances of existential crises and numerous problems during medical studies [11]. Molodynski states that an increased prevalence of poor health varies in accordance with the cultural context, but nevertheless constitutes an international phenomenon among medical students [12]. Cognitive performance and learning capacities depend heavily on physical and mental health [13], and impaired mental health in particular affects academic learning performance [14].

Higher education institutions thus have the task of enabling students to meet the demands of their studies and careers with a broad-based qualification for learning and health promotion. This leads to the development of a profound, demanding, and sustainable learning personality ("sophisticated learners") [15]. Abilities to assume responsibility for, and regulate, one's own studies should be built up in the course of medical training [16]. Intrinsic motivation and curiosity are further determinants of successful learning and should be encouraged [17]. Young doctors in particular describe the experience of meaningfulness in what they do as a key element of burnout prevention [4]. In view of the burnout pandemic among doctors, the World Medical Association amended the Declaration of Geneva in 2017 to include the obligation of physicians to care for themselves: „(...) I WILL ATTEND TO my own health, well-being, and abilities in order to provide care of the highest standard (...)". This represents an important revision in light of emerging need to address and empower physicians' health and self-care capacities.

As described by Ayalya, self-care includes nutrition, physical activity, interpersonal relations, spiritual growth, health responsibility, and stress management. Medical students with higher resilience report improved quality of life and a better perception of their learning environment [18]. The development and promotion of resilience is therefore a valuable strategy to reduce emotional stress and improve medical training [19]. Thus, mental health programs, mindbody skills education, and training programs [20] are increasingly introduced in medical curricula [21-24]. Although showing some effects, the focus of these interventions has been exclusively isolated to one or a few aspects of learning that need to be strengthened. Apart from lack of self-care, students report problems with setting specific learning objectives due to aimlessness, flawed time management, insufficient learning strategies, little self-evaluation and absence of self-motivation; in addition, a lack of intrinsic interest in course content is an obstacle to successful learning [25]. All of these are key competences for selfregulated learning [26], which should be taught for long-term learning and comprehension as they constitute the determinants of successful studies.

This study evaluates a seven weeks longitudinal learning workshop (LW). It has been designed as a holistic model to become aware of and handle factors that influence learning and empower the entire, multidimensional learning life. The broad idea is to educate students how to approach learning holistically and to facilitate learning with increased self-regulation. An adapted and expanded 
version of the model of self-regulated learning (SRL) as a tool of long-term knowledge acquisition [27] is used as the basic concept for processes and didactics. The model is available on request from the first author (MT). The approach of the LW is to combine specific learning techniques with education on how to improve the learning environment [2-3], consider health, meaning, and efficiency, and (re)discover the joy of learning. The LW conveys specific expert knowledge on learning; learning techniques and strategies are presented, individually analyzed and practically trained; individual learning environment and intrinsic motivation for learning are considered. Participants explore the meaning they personally attach to their studies, since learning as a thorough, sustained and lasting process requires that the matter to be learned is of significance to the learner [1]. The didactic concept of the LW therefore relies on diversity of didactical approaches. It comprises keynote speeches, reflection, individual and group work, as well as homework. The focus is on defined tasks, including the transfer of skills into daily activities, the reflection of the achieved personal efficiency and the possibility of a permanent adaption of new skills and tools into students' learning life. The workshop's concept is founded on a pragmatistic learning theory [1] and theories related to learning: principles of the organism, psyche, and the self (adaptive normalization [28]; effort-recovery theory [29], self-determination theory: [30], as well as holistic (medical) anthropological models [31-33]). The training seeks to offer insights into physiological, psychological and mental fields known to contribute to an improved learning environment and to the development of adaptive learning techniques. It does so by taking a holistic approach and by addressing several relevant competencies for adaptive learning - self-reflection, self-regulation, self-care, self-management, and self-development. For a full overview of the topics addressed during LW see table 1: 
Table 1: Overview of the learning workshop

\begin{tabular}{|c|c|c|c|}
\hline Topic & Competency & Content & Examples \\
\hline physical & $\begin{array}{l}\text { Gaining } \\
\text { knowledge on } \\
\text { the physical } \\
\text { determinations } \\
\text { of learning }\end{array}$ & $\begin{array}{l}\text { Nervous system, neuronal } \\
\text { plasticity, access ways to } \\
\text { content and memorization, } \\
\text { learning theories, learning } \\
\text { environment, health and } \\
\text { learning }\end{array}$ & $\begin{array}{l}\text { Usage of diverse access ways, } \\
\text { spaced repetition, Mnemo } \\
\text { techniques, ratio time spent self- } \\
\text { studying /instructional time, work } \\
\text { place and learning conditions }\end{array}$ \\
\hline physiological & $\begin{array}{l}\text { Benefit and } \\
\text { regulation of the } \\
\text { resources of the } \\
\text { organism }\end{array}$ & $\begin{array}{l}\text { Self-care and health, } \\
\text { chronotype, sleep, taking } \\
\text { breaks, exercise, nutrition, } \\
\text { abuse of stimulants }\end{array}$ & $\begin{array}{l}\text { (self-)study time in accordance to } \\
\text { own chronotype, sleep length and } \\
\text { sleeping times, power nap, weekly } \\
\text { rota, study-life-balance with } \\
\text { recreational time, body exercises }\end{array}$ \\
\hline psychological & $\begin{array}{l}\text { Benefit and } \\
\text { regulation of the } \\
\text { psychological } \\
\text { resources to } \\
\text { improve learning }\end{array}$ & $\begin{array}{l}\text { Intrinsic \& extrinsic } \\
\text { motivation, procrastination, } \\
\text { fear, excessive demands, } \\
\text { collaborative learning, } \\
\text { concentration, mental } \\
\text { hygiene, time management }\end{array}$ & $\begin{array}{l}\text { Learning with partners, social } \\
\text { support, digital detoxing, getting } \\
\text { things done, regulation of thoughts } \\
\text { - emotions - volition, treasure } \\
\text { chest }\end{array}$ \\
\hline mental & $\begin{array}{l}\text { Self-realization to } \\
\text { gain insight, } \\
\text { profit and } \\
\text { regulation of } \\
\text { mental resources }\end{array}$ & $\begin{array}{l}\text { Self-reflection, appeal, over- } \\
\text { all goal/mission, spirituality, } \\
\text { awareness and realization } \\
\text { of attitudes, sense-making, } \\
\text { managing meaning }\end{array}$ & $\begin{array}{l}\text { Reflection and adaptation, learning } \\
\text { diary, learning coach, time for own } \\
\text { questions and goals, inner appeal, } \\
\text { meditation \& mindfulness, SMART- } \\
\text { goals and objectives }\end{array}$ \\
\hline
\end{tabular}

To the best of our knowledge, no didactic intervention has been reported so far that can be compared to the holistic approach of the LW. No other intervention known to us tries to explore and foster such a broad spectrum of learning life. Accordingly, no qualitative analysis describes the experience of medical students of such an intervention. The aim of our study is to reveal the immediate effects of the LW on students' learning life. An explorative-evaluative approach was chosen for this purpose without pre-formulated hypothesis. The focus of this study is the identification of regularities based on reflection and evaluation [34], and thus on students' life realities.

\section{Methods}

\section{Setting}

In 2011, the LW was introduced as an elective course in the context of Studium Fundamentale a competence-oriented range of additional studies in humanities, arts, philosophy and other fields that are obligatory for students of all disciplines at Witten/Herdecke University [35-36]. Students learn best whenever they are actively involved in their education [15], thus the development of the LW was and is a joint venture of staff (human and veterinary medicine \& psychology) and students (human medicine, psychology, cultural sciences). Students participate in 
the conceptual design, organization, and teaching of the LW [38]. Student coworkers have been shown to benefit from such an opportunity of learning by teaching [37]. They also have a better understanding of the problems and needs of their participating peers. The longitudinal LW structure comprises one intensive day in class (8 hours) and six subsequent meetings of 90 minutes each on a weekly basis; the schedule may vary in accordance with semester planning. Participants can acquire study credits or equivalent. The seminar concludes without a specific examination, but proof of performance can be issued to gain ECTS (European Credit Transfer and Accumulation System). More information about the concept and the content of the LW is available upon request from the first author (MT).

\section{Study design}

The authors followed the Standards for reporting qualitative research (SROR) in presenting and structuring the research question, data collection, sampling, data analysis and conclusions resulting therefrom [39]. Earlier theories and models on learning are duly considered, but do not dominate, the research process, analysis, or conceptual design. Procedures are inductive and take the form of an iterative research process including regular validation, expansion, and cross-checking by various other researchers.

For the survey, the authors used the Qualitative Short Survey (QSS) method. This instrument of intra-method mixing permits a meaningful combination of qualitative and quantitative data (triangulation). In this manner, subjective findings can be evaluated with the help of quantitative survey data, participants can be assessed individually, groups can be compared, and elaborate statistics can be produced [40].

This type of survey has the following advantages for the present study and the available human and financial resources:

- meaningful format of evaluation which ensures anonymity and reduces distortion in response behavior caused by social desirability, compared to personal in-depth interviews [41]

- allows comparison between different subgroups [42]

- permits time efficient on-site evaluation immediately following the seminar, with a higher response rate than online evaluation at a later time.

\section{Questionnaire}

Assessments by LW participants underwent analysis, and the questionnaire used in this case was specifically designed for evaluation of the LW. It comprises 4 pages with sociodemographic questions, 13 semi-quantitative and three open-ended questions, as well as a self-assessment of one's own abilities and an overall rating. For the purposes of this study, three questionnaire elements (attachment 1) are analyzed asking for a reflection on the development of the respondent's learning behavior and reveal direct information about medical students' learning life.

We used two open-ended questions with the option of free-text answers:

1. Have you noticed any changes in your learning life due to your participation in the LW? If yes, to what extent?

2. How do you evaluate this change in general? (Satisfaction)

And thirdly, a rating on a quantitative scale:

3. The overall grade I give to the $L W$ is (1-6):

(German system of school grades: (1) = Very Good; (2) = Good; (3) =

Satisfactory; (4) = Sufficient; (5) = Poor; (6) = Deficient) 


\section{Data Collection}

Questionnaires were distributed to all participants at the end of the last session of the LW, immediately filled in by students and collected subsequently. Students were informed that participation in the evaluation was voluntary. Completion of the entire questionnaire took between 12 and 18 minutes approximately.

\section{Ethics approval and consent to participate}

Data collection was anonymous. Students were advised that completion and return of questionnaires was voluntary, and that non-participation in the evaluation had no negative consequences for attendance at the LW nor potential proof of performance. Participants were free to decide how much time to invest in completing the questionnaire, how profound, detailed and precise their answers should be, and how much personal information they were willing to give. Thus, informed consent was obtained from all subjects involved in the study. A vote of ethical approval was obtained from the Ethics Committee of Witten/Herdecke University (submission no. 205/December 2019). So, all methods were carried out in accordance with relevant guidelines and regulations.

\section{Sample}

Available evaluations from the summer semester 2011 up to the summer semester 2019 form the basis of this study. Due to organizational reasons, the LW did not take place in every semester but was conducted 17 times. Due to our focus on medical education, only evaluations made by medical students were included in the study. Those by students of other disciplines as psychology, dental medicine, economics and cultural studies were excluded for the study at hand.

Fifty students filled in the evaluation of whom six did not enter their demographic data, but did complete their evaluation. Their answers were included in the qualitative analysis. The response rate was $30.67 \%$. The average age was 22.5 years (between 19 and 30 years of age). Participants $(28 \mathrm{f} / 16 \mathrm{~m}$ ) had completed 2.7 semesters on average (between 1 semester min. and 9 semesters max.).

\section{Data analysis}

Three student assistants and the author (MT) transcribed the answers given in the questionnaire. The basic technique used to analyze the data is the qualitatively oriented content-analytical method of structuring content analysis with subsequent frequency analysis in adherence to Mayring [43]. Following this method, an iterative step-by-step procedure served to inductively develop a system of categories. The authors used the computer software MAXQDA2018 to analyze complex non-numerical data [34]. The software SPSS Statistics 25 was used for the quantitative analyses for research question number three and the descriptive demographics statistics.

The content-analytical criterion of inter-coder reliability was applied to test the reliability of qualitative findings. Data was comprehensively analyzed by a researcher who is experienced with the method (MT) and two students (MB \& RS) who assisted in the design and the conduct of the LW. They analyzed a randomized excerpt of the data to permit the inclusion of the student perspective on the findings in the process of analyzing and interpreting results. Two other researchers, familiar with the method, encoded up to $50 \%$ each of the entire data material (DT \& FA). Assignment of material was randomized. As a consequence, the coding-team was a heterogenous group of various researchers with different personal and professional experiences and preconceptions resulting therefrom [44]. 
The five encoding schemes were disclosed, presented, jointly considered, and discussed in an inter-coder-reliability-team meeting. The researchers specifically tried to identify divergencies in the interpretation of terminology and thus to obtain a clear picture of the respective degree of subjectivity in such interpretations (Hannes, 2010). Excerpts from the material were studied together to see whether essential qualities of students' statements had been appropriately and congruently summed up in encoding. The emerged encoding schemes coincided; incongruous notions were defined more distinctly. Discussion topics were conclusiveness, precision, and logical congruence in the definition of the encoding schemes and encoding guidelines. Congruent and contradictory elements of the five coding schemes were debated, and mutually agreed definitions were established. Based on this the definitions a final encoding scheme and encoding guideline were finalized by MT and used in the further elaboration of the model and the analysis [43].

\section{Results}

\section{Qualitative survey}

Responses were heterogenous in terms of length, form, and depth. Some evaluations were short lists of key aspects. Other participants wrote long paragraphs using full sentences. All quotes were translated and back translated from German to English for publication purpose.

The structuring qualitative content analysis [43] yielded the following results: In total, the LW had a fundamental and comprehensive impact on various levels of learning. Participants could precisely describe effects and also triggers for the changes they register in their own learning life. No respondent left questions unanswered. Nobody reported any declining or negative trends in learning as a consequence of attending the LW.

Individual students reported frustrating realizations about deficits in their own learning behavior which the contents and exercises of the LW helped them to address:

"I have started to learn. Looking back to the past semesters, I somehow muddled through, and I realized that this is not really an option (result: failed MEQ1 - MEQ2). What I took home from the LW were many "small" things, techniques and suggestions, e.g. a fixed learning schedule, power napping, continuous repetition; I also realized that other techniques do not really appeal to me (such as mind mapping). I would say that my way of learning has become more regular, comprehensive, consistent and effective, and I feel better with that. But there are still some aspects that I need to optimize." (participant no. 10)

Note from the author: At Witten/Herdecke University, the 1st medical state examination is replaced by three MEQ tests (Modified Essay Question Test) in combination with two OSCE exams (Objective Structured Clinical Examination), pursuant to the pertinent clause in licensing regulations (ÄAppO) on medical model curricula.

Five key dimensions of impact emerged in the qualitative analysis where students registered changes due to attendance at the LW: knowledge, awareness, action, experience and regulation. Notably, none of these dimensions was mentioned distinctly more often or predominantly, and therefore is of greater relevance compared to the others. Table 2 illustrates the code groups with pertinent definitions, corresponding encodings, and the identified frequencies: 
Table 2: Overview: Perceived dimension of impact and core aspect of the results

\begin{tabular}{|l|l|c|}
\hline $\begin{array}{l}\text { Dimension of } \\
\text { impact }\end{array}$ & Core aspect & $\begin{array}{c}\text { Percentage } \\
\text { distribution }\end{array}$ \\
\hline $\begin{array}{l}\text { Dimension of } \\
\text { knowledge }\end{array}$ & $\begin{array}{l}\text { I have acquired new knowledge } \\
\text { about learning. }\end{array}$ & $23 \%$ \\
\hline $\begin{array}{l}\text { Dimension of } \\
\text { awareness }\end{array}$ & I have become aware of something. & $18 \%$ \\
\hline $\begin{array}{l}\text { Dimension of } \\
\text { action }\end{array}$ & $\begin{array}{l}\text { I try out other ways of learning for } \\
\text { myself, under supervision and/or } \\
\text { together with others. }\end{array}$ & $18 \%$ \\
\hline $\begin{array}{l}\text { Dimension of } \\
\text { experience }\end{array}$ & $\begin{array}{l}\text { I experience change in my learning } \\
\text { life. }\end{array}$ & $24 \%$ \\
\hline $\begin{array}{l}\text { Dimension of } \\
\text { regulation }\end{array}$ & $\begin{array}{l}\text { I act with intention to achieve the } \\
\text { goal I have set myself. }\end{array}$ & $17 \%$ \\
\hline
\end{tabular}

\section{Dimension of knowledge}

I have acquired new knowledge about learning. Participants reported that attendance resulted in additional theoretical knowledge about learning which they perceived as helpful, guiding, and supportive. A total of $23 \%$ of all references concern this dimension. More than half of participants (62\%) mentioned aspects which are associated with the knowledge dimension. Students reported that this additional knowledge made their learning more efficient and effective. Key terms mentioned in this context were various structuring learning techniques, power napping, weekly schedule, mind mapping, treasure box (award), meditation, rhythms, and the significance of joy in learning, as well as intrinsic motivation.

"The LW has brought about major changes in the way I learn.

I have received helpful suggestions for learning methods which I have put into practice. (...).“(Participant no. 36)

\section{Dimension of awareness}

I have become aware of something. Students described positive developments on this dimension due to the LW. The reasons provided were growth in theoretical knowledge and the assignments to be addressed on the one hand, and on the other, the exploration of one's own attitude, motivation and learning environment. What emerged from these reflections was an enhanced awareness of the personal learning processes. The core elements named by participants were: reflection of learning preferences, questions of meaning, the self, one's own learning behavior, contemplation, self-care. Specifically, joint reflection with others is described as meaningful. This dimension accounted for $18 \%$ of references, and $66 \%$ of participants rated experienced changes at this dimension as relevant. 
my daily life in general.

- intentional learning means that I organize my learning proactively and do not just get started. This way is more fun, I feel structured and more myself and more efficient, and therefore more motivated

- I pay attention to sleep and get up in the morning feeling fresh. What's new is that I get up earlier but nevertheless well rested. Every day around noon I take a nap for 15 minutes, which I look forward to and which gives me lots of energy.

- I have an excellent weekly schedule which I admit I haven't followed as strictly as earlier in the semester. Power and motivation for organization and activity tend to decline. Now I am looking forward to the Christmas break.

- Obviously, it takes effort and energy to become proactively engaged. I did not do much of that before. "(Participant no. 127)

"With a focus on my motivation, learning has become easier and more of a pleasure!” (Participant no. 74)

\section{Dimension of action}

I try out other ways of learning for myself, under supervision and/or together with others. Students tested various learning methods collaboratively during the seminar under supervision, and jointly discussed individual experiences with their peers. Participants report that in this manner the LW opened up new options for action. Positive key terms in this context were: effectiveness, productivity, concentration, learning group and regular breaks. Obstacles to be faced at this dimension are implementation problems and lack of discipline. A total of $18 \%$ of the responses refer to the dimension of action. More than half of the students (64\%) report changes at this dimension triggered by the LW. Exchange with fellow students was specifically mentioned as a helpful element.

"I tried new ways of learning. 1. I discovered mindmapping for example as a good tool for me, which I knew before LW but didn't really like. 2. We created a learning team and tried to learn collaboratively. 3. I minimized my physical personal attendance at lectures. 4 . I tried intercommunication with students from higher semesters. The LW supported that. 5. I started reflecting on my personal learning behavior: What is good an what is bad? 6. I learned new ways of pre- and postprocessing of the lectures and the problem-basedlearning-cases. That helped me a lot with remembering and aided recall." (Participant no.4)

"Exchange with other course participants has given me a feeling of safety. It was reassuring to hear from others in the plenary session that they basically grapple with problems/difficulties in learning similar to my own. That was really good to know.” (Participant no. 16)

\section{Dimension of experience}

I experience change. Participants described several areas of practical experience as triggers of change. Most quoted is the dimension of emotions/feelings for negative as well as positive experiences, or changes in affect. Students report enhancement received in the LW to reconsider their learning approach. The individual nature of responses referring to this dimension was interesting to note. Key terms in this context were: enjoyment, courage, motivation, anxiety, selfconfidence, insecurity, health, sense of well-being, more positive attitude and 
stress reduction. Most students (68\%) report that they registered changes in experience, feelings and attitude as a consequence of the LW. A total of $24 \%$ of all responses referred to this category.

"My attitude towards learning and motivation to study have improved as well. Now learning is more fun, and I repeatedly remind myself that studying is what I want to do and what I enjoy, and not just misery. My test anxiety is not as bad as before. I will definitely follow the advice how to manage the test situation better (e.g. by bringing objects which improve well-being). I am really glad and grateful for this seminar; it was immensely helpful to optimize learning time and learning performance." (Participant no. 36)

\section{Dimension of regulation}

I act with intention to achieve the goal I have set myself. Participants described the newly addressed capacity for self-regulation as an important trigger for change. Interesting to mention was, that students characterized self-regulation skills as the primary key to perceived changes at all other dimensions. The dimension of regulation could be called a superordinate dimension in relation to dimensions 1 to 4 . It could therefore be assumed to have a broader basis than indicated by $17 \%$ of all responses and $60 \%$ of respondents, since the capacity for regulation is implicitly contained in the aspects described for dimensions 1 to 4 . Key terms were: regulation of learning periods, time management, time out and sleep (adaptation). These are the most quoted aspects (36 responses). Digital detoxing (i.e. more deliberate and regulative use of digital media) is a further aspect mentioned in more recent surveys.

"I have put some suggestions into practice, and I do no longer feel controlled by stress but rather in control of what I am doing." (Participant no. 24)

"Now I have got more structure, I know how to tackle a problem and not to panic. (...) I would like to establish these learning techniques more firmly and make a habit of sticking to the weekly schedule."(Participant no. 74)

The importance of the dimension of regulation is shown again in the fact, that this dimension was the only one where students registered negative experiences as well. But it was not the subject matter of the LW which was perceived as negative; rather, students report a negative affect which they specifically perceived at the second (awareness), third (action), and fourth (experience) dimensions. Students indicated that the LW has helped them to develop an awareness of their own limitations in regulatory skills; it is frustrating for them to see that they are unable to use these skills to the desired extent. Other private reasons were also given for negative experiences, such as prolonged illness or mobbing by fellow students.

„(...)a more deliberate approach in my learning behavior / assessment of my learning strategies

- have been given a lot of tools and have to try them out -> do no longer feel so overwhelmed because now I know lots of options how to tackle the matter. What is still lacking is the courage to actually apply these strategies (...) I feel that I am able and willing to change some things. Some things have already changed, and I like that, but I have not yet reached the point where I can say I have got a satisfactory learning strategy." (Participant no. 26) 


\section{Satisfaction}

Students report many changes they have experienced in their learning life. In response to the question whether participants are satisfied with the changes they perceive, $84 \%$ ( 42 out of 50 ) say they are satisfied. $6 \%(\mathrm{~N}=3)$ do not respond. $2 \%$ $(\mathrm{N}=1)$ say Yes and $N o$, and $10 \%(\mathrm{~N}=5)$ say they are not satisfied. But the reasons given by $80 \%$ of these unsatisfied participants $(\mathrm{N}=5)$ reveal that their lack of satisfaction refers not to content or format but to their own regulatory deficits. It appears that they perceive seminar contents as meaningful but they have not found the strength to put them into practice. One dissatisfied participant did not give any further information.

\section{Quantitative results}

The overall evaluation is based on the German system of school marks ( $1=$ very good/top mark, 6 = deficient/bottom mark) and aims to interpret medical students' assessment of changes resulting from their participation in the LW.

Fifty students filled out the questionnaire. Two respondents $(\mathrm{N}=2)$ did not provide an overall mark. The LW is generally rated as "good" (median $=2.00$; mean $=1.63)$. The statistical spread of results ranges from " $1=$ very good" to " 3 =satisfactory" (IQR 1.0; SD 0.64). As figure 1 depicts, the distribution of marks is skewed towards good marks - most students rate the LW as very good and good. Only a few of the ratings give 3 as an overall evaluation. A mark below "satisfactory" was not given.

Figure 1: Overall Satisfaction with LW

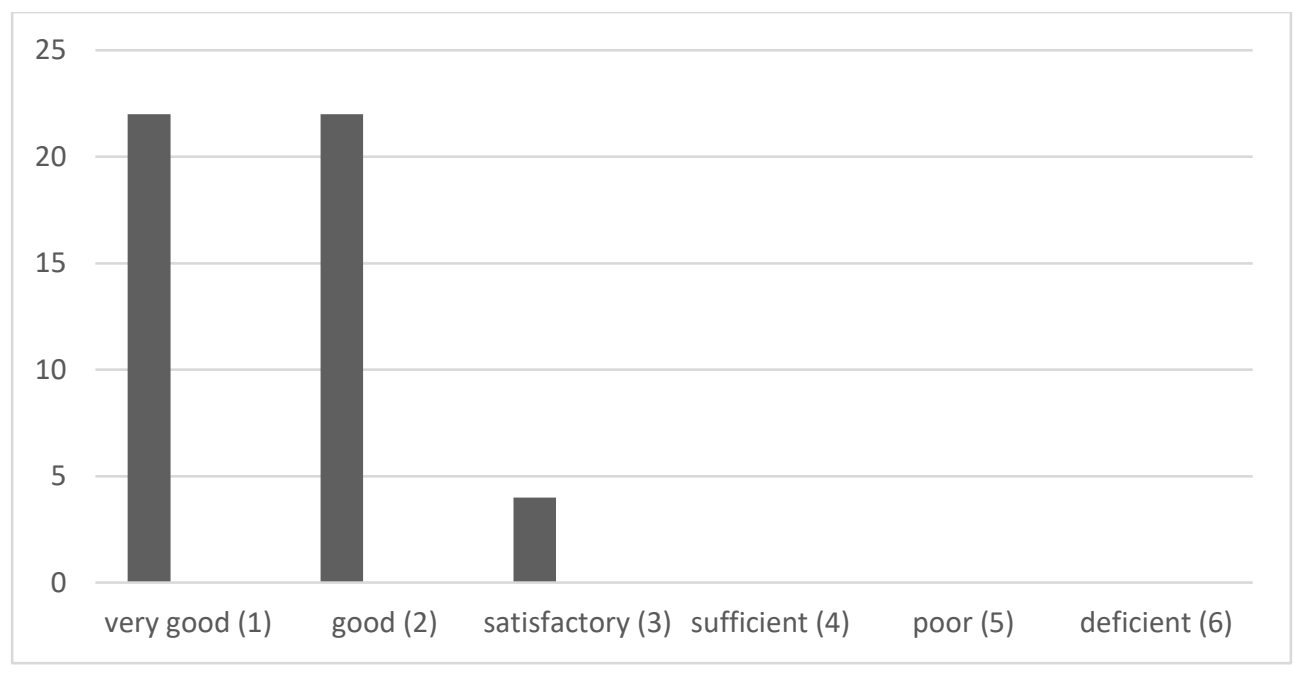

\section{Discussion}

Students who attend the LW report experienced changes on five core dimensions: knowledge, awareness, action, experience and regulation. It is interesting to note that the dimension of regulation or rather the empowerment for self-regulation seems not to be on the same level as the other four dimensions, as regulating is a higher capacity. Findings reported by Schunk and Zimmerman [26] indicate that this capacity for regulation, combined with - for example - precise targets, selfevaluation, intrinsic interest, and adaptation of learning strategies, is a fundamental pre-requisite for meaningful long-term learning and thus for successful academic studies. In addition of being a pre-requisite as described, we question if the first four above mentioned dimensions are necessary pre-requisites that contribute to the growing of this regulating capacity, and therefore it would be fundamental that they are addressed in order to promote the development of the 
(self-regulated) learning capacity of students.

Self-determination is another key issue for students. The three basic psychological needs - competence, social integration, and autonomy - inherent in the SelfDetermination Theory (SDT [30]) are reflected in the answers given by participants in our study. According to Deci and Ryan, the fulfilment of these needs has an immediate motivating impact on creativity, problem-solving abilities, staying power and the accompanying sense of well-being [30]. If these needs are not met, students may feel frustrated and less motivated, and ultimately experience a decline in well-being and health, which can in turn results in an absolute lack of drive. As to improvements in the learning environment, they mention - among other things - scope for personal initiative, comprehensible reasons for the subject matter to be addressed, waiver of performance comparison or performance-related rewards, and avoidance of overstrain and underchallenge. Participants' responses indicate that the LW stimulates their basic psychological needs outlined in the SDT, with positive effects on process-orientation as well as associated motivational aspects of learning. It conveys knowledge about learning per se, encourages active participation, trying out, reflecting and adapting, and therefore the development of learning skills (competence). It brings students together inter- and intra-professionally and at different levels of their studies, and invites participants to collaborative exploration and reflection (social integration). In addition, the LW permits students to decide for themselves which learning suggestions to implement in the practice of their individual learning behavior (autonomy).

The concept of Learning environment refers to the entirety of study conditions. These comprise amongst others students' social networks (participation in social life), and their intra-psychological world with all emotions as fear, beliefs etc. involved (environment [3, 46]). The answers provided by participating students in this study underline that it is necessary to integrate these learning environmental aspects into the metacognitive process of learning how to learn. Students' health as a basic element of learning capacity should be strengthened, and resilience should be promoted to ensure long-term successful learning [14, 19, 47]. We know for example. that intrinsic motivation and curiosity [17], a sense of meaningfulness [4] and self-care [18] are important determinants of successful learning. Beyond that, the individual learning life could be taken into account if students are to experience the life period of their studies as efficient, healthy and meaningful in the long-run. Learning life can be defined as the sum of all the factors in daily life influencing every students' daily academic performance. The individual physiology, body, psychology, mentality and spirituality should be worthy to taken into account on the dimensions of knowledge, awareness, action, experience and regulation when aiming to augment learning. It appears to be important in the didactics of medical education to highlight and address all dimensions of the learning life, the environment, and the close relations between studies and private life [48]. Moreover, individual learning behavior is characterized by interaction between various areas of life as the personal, social, biological \& the psychological area [25]. The participants of the study at hand depicted the significance of this interaction in detail. Results show that the issues addressed in the LW stimulate significant processes of change in students.

\section{Strengths and limitations of the study}

Strengths and limitations of the research process and the findings are as follows:

Qualitative Short Survey (QSS) was used to collect the data for the study. This 
instrument of intra-method mixing permits a meaningful combination of qualitative and quantitative data (triangulation [40]. The QSS is an expedient format of evaluation which ensures anonymity and reduces potential distortion in response behavior caused by social desirability, compared to personal in-depth interviews [41]. It is, however, less detailed and differentiated than interviews. However, the method served to generate a large number of participants and provided a wide view of students' personal experiences. Qualitative in-depth interviews or focus-group interviews may be suitable instruments to further deepen and differentiate the insights gained in this manner.

Above that, numerous steps were taken to improve the validity of results gained by the qualitative methods. However, it is important to note that the process of interrater validation revealed differences in the use of key terms such as effectiveness and efficiency. Application of these terms was congruent in some questionnaires, and divergent in others. Some respondents left the definition open; others used the terms incongruently within their reply. For further considerations of the coding model development, the authors agreed on the following definitions, in adherence to definitions by Dyckhoff and Souren [49] and adapted to learning contexts of tertiary education: effectiveness stands for "I can achieve my goal and know the required ways and means", whereas efficiency corresponds to the basic assumption "I can achieve my goal with as few resources as possible". These definitions have been agreed upon and maintained by all researchers involved for subsequent activities. The scheme is not $100 \%$ precise even after good validation, but suitably reflects the realities of student life.

In the overall interpretation of the results, it should be noted that the time frame chosen for the survey right at the end of the LW could be too short to make accurate statements about profound and lasting changes. This limitation, however, is also a strength since memories are still fresh at that time, and therefore relatively unaffected by cognitive distortion. A survey on long-term changes to be conducted e.g. six months after the end of the longitudinal seminar might serve to obtain further insights.

Didactic concepts in the medical curriculum should take students' learning environment and learning life into consideration. This could enhance the conveyance of subject knowledge. The formation of healthy, competent, emphatic, purposeful, capable, and motivated physician personalities could require that medical students receive training in the fields of learning theory and practice with self-reflection, awareness, organization, and development of their individual learning life. Medical students seem to long for guidance in trying out and adapting suggestions, so they can experience and reflect processes of change at physiological, psychological, and mental levels. The LW may serve as a model example of a longitudinal seminar to be taken up by other universities. Being transferable, it can be adapted to specific locations and situations. It can help to develop clinicians with excellent academic training at the service of society and empower them to make a positive contribution.

\section{Conclusions}

This study investigated an elective longitudinal learning workshop with an anthropologically grounded multidimensional approach to foster learning capacities. Semi-quantitative results demonstrated good satisfaction with the workshop; qualitative results revealed the impact on five dimensions on medical students' progress of learning capacities: knowledge, awareness, action, 
experience and regulation. Findings from this study were directly generated from medical students' perceptions and experiences. Resulting implications provide interesting suggestions for the curricular design and development of medical education. It appears that a holistic, methodological, and thematic approach of this type has not yet been sufficiently developed or rather included in the exploration of the contemporary learning culture. Influencing academic performance by addressing the entire learning life should therefore be considered as a concept of some relevance for further efforts in supporting students' academic learning in future research. This study is intended as a first step in a new direction of understanding the concept of learning and a basis for further research activities and publications.

One of the participants puts the experienced impact of the LW in a nutshell:

"The LW [learning workshop] has opened my eyes (...) that learning takes time but there is no need to neglect other aspects of life. I see that I can make changes, now I do no longer feel hung up in a downward cycle although the way to the top is still long." (Participant no. 15) 


\section{Declarations}

Ethics approval and consent to participate

Data collection was anonymous. Students were informed that completion and return of questionnaires was voluntary, and that non-participation had no negative consequences for attendance at the LW nor potential proof of performance. Participants were free to decide how much time to invest in completing the questionnaire, how detailed their answers should be, and how much personal information they were willing to give. Thus, informed consent to participate was given (attachment 2). A vote of approval was obtained from the Ethics Committee of Witten/Herdecke University (submission no. 205/December 2019).

Consent for publication

Not applicable

Availability of data and materials

The datasets used and/or analyzed during the current study are available from the corresponding author on reasonable request. The students' free-text answers are in German. There is no complete translation of all transcripts. Data was stored according to the agreements with participants and the ethical standards.

Competing interests

The authors declare that they have no competing interests.

Funding

There was no funding for this study.

Authors' contributions

MT planned and conducted the study, analyzed the data and was the main author of the manuscript. DT founded the LW, prepared the evaluation, collected the data and contributed to the discussions during the analysis process and the manuscript writing process. Both authors read and approved the final manuscript.

Acknowledgements

The authors want to thank the ICURAM (Integrated Curriculum for Anthroposophic Medicine) at Witten/Herdecke University for supporting the study. The authors want to thank all contributors, teachers, students and supporters of the LW, esp. all the students who engaged to conceptualize, realize, and co-conduct the $\mathrm{LW}$, and contributed within. Thank you also to Christina Wagner for linguistic assistance in preparing the English version of the paper. To Merle Bening and Ronja Serian, two advanced psychology student assistants in the research project "Learning how to learn" and LW instructors, who enhanced the study with their student perspective on our research. To Melanie Neumann, Kirill Fayn and Florian Ahrweiler who supported our scientific process and development a lot. Last but not least the authors want to thank all medical students who shared their private experiences and contributed with their answers to the study.

Authors' information

Miriam Thye: psychologist, PhD candidate, coordinator of the research project "Learning how to learn", LW instructor (miriam.thye@uni-wh.de) \& Diethard Tauschel: physician, in charge of LW and ICURAM, LW instructor (diethard.tauschel@uni-wh.de).

More information: https://lernenlernen.uni-wh.de/ 


\section{References}

1. Faulstich P. Menschliches lernen: Eine kritisch-pragmatistische lerntheorie. Transcript Verlag;2014.

2. Gruppen L, Irby D, Durning S, Maggio L. Interventions Designed to Improve the Learning Environment in the Health Professions: A Scoping Review. MedEdPublish. 2018;7(3).

3. Hattie J, Donoghue G. Learning strategies: a synthesis and conceptual model. npj Science of Learning. 2016;1(1).

4. Shanafelt T, Noseworthy J. Executive Leadership and Physician Well-being: nine organizational strategies to promote engagement and reduce burnout. Mayo Clinic Proceedings. 2017;92(1):129146.

5. Lyndon M, Henning M, Alyami H, Krishna S, Zeng I, Yu T et al. Burnout, quality of life, motivation, and academic achievement among medical students: A person-oriented approach. Perspectives on Medical Education. 2017;6(2):108-114.

6. Heinen I, Bullinger M, Kocalevent R. Perceived stress in first year medical students - associations with personal resources and emotional distress. BMC Medical Education. 2017;17(1).

7. Voltmer E, Kieschke U, Schwappach D, Wirsching M, Spahn C. Psychosocial health risk factors and resources of medical students and physicians: a cross-sectional study. BMC Medical Education. 2008;8(1).

8. Mundle G. Wie Ärzte gesund bleiben- Resilienz statt Burnout. Stuttgart: Georg Thieme Verlag; 2015.

9. Thomas L, Ripp J, West C. Charter on Physician Well-being. JAMA. 2018;319(15):1541.

10. Frajerman A, Morvan $Y$, Krebs M, Gorwood $P$, Chaumette B. Burnout in medical students before residency: A systematic review and meta-analysis. European Psychiatry. 2019; 55:36-42.

11. Mata D, Ramos M, Bansal N, Khan R, Guille C, Di Angelantonio E et al. Prevalence of Depression and Depressive Symptoms Among Resident Physicians. JAMA. 2015;314(22):2373.

12. Molodynski A, Lewis T, Kadhum M, Farrell S, Lemtiri Chelieh M, Falcão De Almeida T et al. Cultural variations in wellbeing, burnout and substance use amongst medical students in twelve countries. International Review of Psychiatry. 2020;1-6.

13. Shapiro S, Brown K, Biegel G. Teaching self-care to caregivers: Effects of mindfulness-based stress reduction on the mental health of therapists in training. Training and Education in Professional Psychology. 2007;1(2):105-115.

14. Dekker I, De Jong E, Schippers M, De Bruijn-Smolders M, Alexiou A, Giesbers B. Optimizing Students' Mental Health and Academic Performance: Al-Enhanced Life Crafting. Frontiers in Psychology. 2020;11.

15. Bjork RA, Yan VX. The increasing importance of learning how to learn. In: McDaniel MA, Frey RF, Fitzpatrick SM, Roediger HL, editors. St Louis: Washington University; 2014. p. 15-36.

16. Zimmerman BJ, Schunk DH, DiBenedetto MK. The role of self-efficacy and related beliefs in selfregulation of learning and performance. Handbook of competence and motivation: Theory and application. 2017;313.

17. Oudeyer P-Y, Gottlieb J, Lopes M. Intrinsic motivation, curiosity, and learning: Theory and applications in educational technologies. Progres in Brain Ressearch. 2016; 229:257-84.

18. Ayala EE, Winseman JS, Johnsen RD, Mason HR. US medical students who engage in self-care report less stress and higher quality of life. BMC medical education. 2018;18(1):189.

19. Tempski P, Santos IS, Mayer FB, Enns SC, Perotta B, Paro HBMS, et al. Relationship among medical student resilience, educational environment and quality of life. PLoS One. 2015;10(6):e0131535.

20. Wasson LT, Cusmano A, Meli L, Louh I, Falzon L, Hampsey M, et al. Association between learning environment interventions and medical student well-being: A systematic review. JAMA.

2016;316(21):2237-52. 
21. Rosenthal S, Howard B, Schlussel YR, Herrigel D, Smolarz BG, Gable B, et al. Humanism at heart: preserving empathy in third-year medical students. Acad Med. 2011;86(3):350-8.

22. Moir F, Henning M, Hassed C, Moyes SA, Elley CR. A peer-support and mindfulness program to improve the mental health of medical students. Teach Learn Med. 2016;28(3):293-302.

23. Wald HS, Haramati A, Bachner YG, Urkin J. Promoting resiliency for interprofessional faculty and senior medical students: Outcomes of a workshop using mind-body medicine and interactive reflective writing. Med Teach. 2016;38(5):525-8.

24. Greeson JM, Toohey MJ, Pearce MJ. An adapted, four-week mind-body skills group for medical students: reducing stress, increasing mindfulness, and enhancing self-care. Explore (NY). 2015;11(3):186-92.

25. Thye M, Ritzka D, Link R, Tauschel D. "Learning how to learn" - Which learning techniques really foster contemporary academic learning? The European Proceedings of Social and Behavioural Sciences. 2016; 2357-1330.

26. Schunk DH, Zimmerman BJ, editors. Motivation and self-regulated learning: Theory, research, and applications. Routledge; 2012.

27. Zimmerman BJ. Becoming a self-regulated learner: An overview. Theory Pract. 2002;41(2):64-70.

28. Heckmann C, Gutenbrunner C. unktionelle Hygiogenese: Grundlage der adaptiven Normalisierung. VAS Verlag für Akademische Schriften; 2013.

29. Meijman TF, Mulder G, Drenth P, Thierry H. Psychological aspects of workload. Handbook of work and organizational psychology. 1998;2.

30. Deci EL, Ryan RM. Self-Determination Theory. In: Handbook of Theories of Social Psychology: Volume 1. 1 Oliver's Yard, 55 City Road, London EC1Y 1SP United Kingdom: SAGE Publications Ltd; 2014. p. 416-37.

31. Heusser P. Anthroposophy and Science: An Introduction. Frankfurt, Bern, New York: Peter Lang; 2016.

32. Girke M. The concept of the human being. Internal medicine, foundations and therapeutic concepts of anthroposophic medicine. Berlin: Salumed Verlag; 2016.

33. Steiner R, Wegman I. Extending practical medicine: fundamental principles based on the science of the spirit. Rudolf Steiner Press; 1997.

34. Rädiker S, Kuckartz U. Analyse qualitativer Daten mit MAXQDA: Text, Audio und Video. 1st ed. Wiesbaden, Germany: Springer Fachmedien Wiesbaden; 2018.

35. Butzlaff M, Hofmann M, Edelhäuser F, Scheffer C, Tauschel D, Lutz G, et al. Der Modellstudiengang Medizin an der Universität Witten/Herdecke-auf dem Weg zur lebenslang lernfähigen Arztpersönlichkeit. Handb. Qual. Stud. Lehre. Berlin: Raabe-Fachverlag für Wissenschaftsinformation; 2014.

36. Frost K, Edelhäuser F, Hofmann M, Tauschel D, Lutz G. History and development of medical studies at the University of Witten/Herdecke - an example of "continuous reform." 2019; Available from: http://dx.doi.org/10.3205/ZMA001269

37. Renkl, A. Lernen durch Lehren. Deutscher Universitätsverlag; 1997.

38. Christenson SL, Reschly AL, Wylie. Handbook of research on student engagement. C, editor. Springer Science \& Business Media; 2012.

39. O'Brien BC, Harris IB, Beckman TJ, Reed DA, Cook DA. Standards for reporting qualitative research: a synthesis of recommendations. Acad Med. 2014;89(9):1245-51.

40. Neumann M. Qualitative Short Survey (QSS). In: Wirtz MA, editor. 16th ed. Bern: Verlag Hans Huber; 2013.

41. Dillman DA. Mail and Internet surveys: The tailored design method--2007 Update with new Internet, visual, and mixed-mode guide. John Wiley \& Sons; 2011.

42. Neumann M, Goldblatt H, Edelhäuser F, Lutz G, Scheffer C. The Qualitative Short Survey (QSS)-A new method for regular evaluation in health communication. Med Encount. 2011; 25:67-68. 
43. Mayring P. Qualitative Inhaltsanalyse - Grundlagen und Techniken. Beltz Verlag. Weinheim Basel; 2015.

44. Dunkelberg S. Wie gut ist eine qualitative Studie? 10 hilfreiche Fragen für den Leser von Aufsätzen. ZFA (Stuttgart). 2005;81(6):248-51.

45. Hannes K, Lockwood C, Pearson A. A comparative analysis of three online appraisal instruments' ability to assess validity in qualitative research. Qual Health Res. 2010;20(12):1736-43.

46. Isba R. Creating the learning environment. In: Oxford Textbook of Medical Education. Oxford University Press; 2013. p. 100-10.

47. Tempski P, Bellodi PL, Paro HB, Enns SC, Martins MA, Schraiber LB. What do medical students think about their quality of life? A qualitative study. BMC Med Educ. 2012;12(1).

48. Schmidt CE, Möller J, Schmidt K, Gerbershagen MU, Wappler F, Limmroth V, et al. Generation Y: recruitment, retention and development: Rekrutierung, Entwicklung und Bindung. Anaesthesist. 2011;60(6):517-24.

49. Dyckhoff H, Souren R. Main Performance Categories: Effectiveness and Efficiency. In Cham: Springer; 2020. p. 1-18. 
Figures

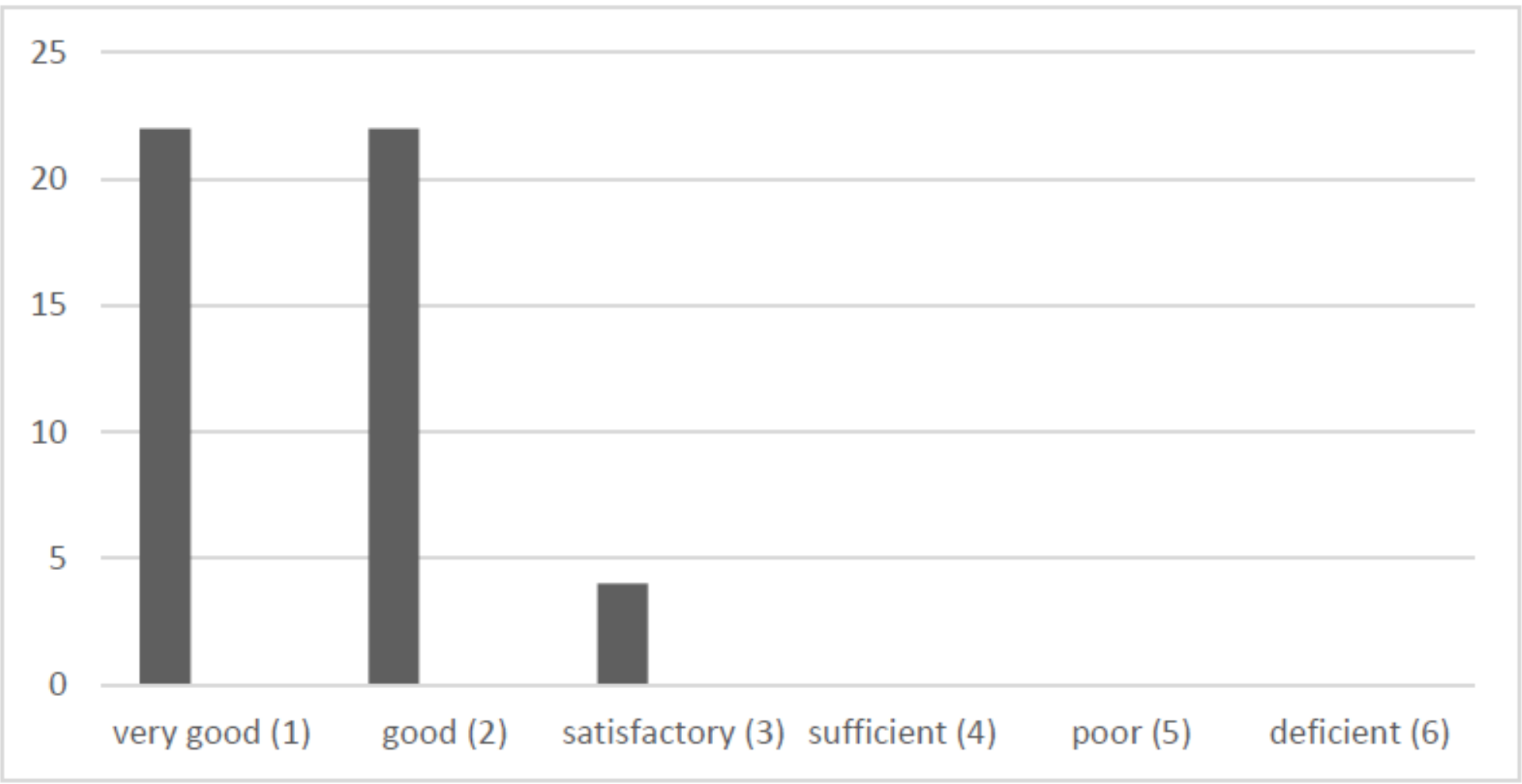

Figure 1

Overall Satisfaction with LW 